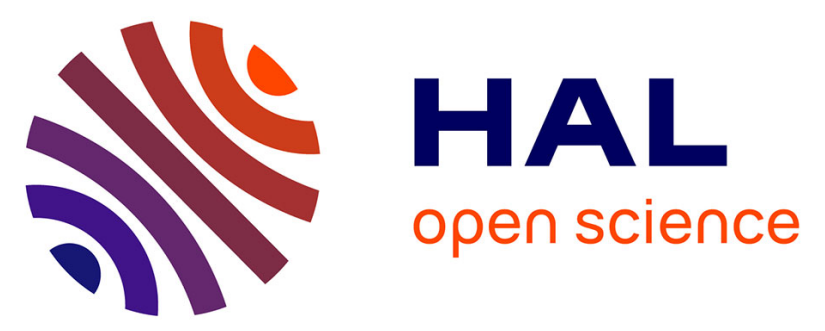

\title{
Controlling the distribution of fire retardants in poly(lactic acid) by fused filament fabrication in order to improve its fire behaviour
}

\author{
Arnaud Regazzi, Monica Francesca Pucci, Loïc Dumazert, Benjamin Gallard, \\ Sylvain Buonomo, Romain Ravel, José-Marie Lopez-Cuesta
}

\section{To cite this version:}

Arnaud Regazzi, Monica Francesca Pucci, Loïc Dumazert, Benjamin Gallard, Sylvain Buonomo, et al. Controlling the distribution of fire retardants in poly(lactic acid) by fused filament fabrication in order to improve its fire behaviour. Polymer Degradation and Stability, 2019, 163, pp.143-150. 10.1016/j.polymdegradstab.2019.03.008 . hal-02424968

\section{HAL Id: hal-02424968 \\ https://hal.science/hal-02424968}

Submitted on 26 Feb 2020

HAL is a multi-disciplinary open access archive for the deposit and dissemination of scientific research documents, whether they are published or not. The documents may come from teaching and research institutions in France or abroad, or from public or private research centers.
L'archive ouverte pluridisciplinaire HAL, est destinée au dépôt et à la diffusion de documents scientifiques de niveau recherche, publiés ou non, émanant des établissements d'enseignement et de recherche français ou étrangers, des laboratoires publics ou privés. 


\title{
Controlling the distribution of fire retardants in poly(lactic acid) by fused filament fabrication in order to improve its fire behaviour
}

\author{
Arnaud Regazzi, Monica Francesca Pucci, Loic Dumazert, Benjamin Gallard, \\ Sylvain Buonomo, Romain Ravel, José-Marie Lopez-Cuesta*
}

C2MA, IMT Mines Alès, Univ Montpellier, Ales, France

\begin{abstract}
A B S T R A C T
This study focused on the development of skin/core structures with flame-retarded poly (lactic acid) (PLA) compositions, by additive manufacturing. For this purpose, the technique of Fused Filament Fabrication (FFF) was chosen. Plate samples were also manufactured by injection moulding for comparison purpose. The nature of the flame retardants (FR), their contents and their distribution in the samples were varied. The fire behaviour was investigated by cone calorimeter tests. The microstructure was characterized and related to the fire performances of each flame-retarded PLA structure. The results showed a significant decrease of the time to ignition (TTI) of 3D printed samples compared to the injected ones, due to their higher porosity. However, for a given total FR content, concentrating FR close to the radiated surface proved to be a promising solution in order to optimize fire performance while preserving the mechanical properties of neat PLA.
\end{abstract}

Keywords:

Additive manufacturing

3D printing

Bio-based polymers

Fire behaviour

Flame-retardants

\section{Introduction}

Poly (lactic acid) (PLA) can be considered to be one of the main biobased polymers used in fused filament fabrication (FFF), analogous to fused deposition modelling $\left(\mathrm{FDM}^{\circledR}\right)$ [1]. As many polyesters, the increase of its use in many applications such as electronics, transportation and building requires its fire behaviour to be improved [2-4]. Intumescent systems based on ammonium polyphosphate and melamine have proved to be effective to improve significantly the fire performance of PLA. Moreover, adding nanofillers, such as montmorillonite and sepiolite, can create synergistic effects on fire properties [5-11].

Nevertheless, high percentages of flame retardants (FR) tend to be detrimental to the ultimate mechanical properties [6]. To overcome these drawbacks, FFF technology allows skin/core structures to be produced in which flame retardant systems can be located only at the surface of the material exposed to the flame or radiant heat. These dual structures can be formed using dual extruder printers, enabling the sequential deposition of the core and the skin part. Therefore, it is possible to control the skin thickness in order to evaluate its influence on fire performance [12].

\footnotetext{
* Corresponding author.

E-mail address: jose-marie.lopez-cuesta@mines-ales.fr (J-M. Lopez-Cuesta).
}

It is known from literature that flame retarded multi-materials and skin/core parts can be also obtained through various manufacturing processes such as co-injection moulding technology, press stacking and coating [13]. Flame retarded materials corresponding to sandwich structures or core-skin parts have been produced using these processing techniques by various authors [14-18]. However, for only a part of these works $[14,16,18]$, the polymer corresponding to the skin was the same as this of the core. Moreover, in the case of intumescent coatings the substrate is generally metallic and not a polymer [17].

In comparison with these polymer processing techniques, FFF proves to be an advantageous direct and continuous process [19], allowing a better control of the skin thickness compared to a coating and the production of complex parts (3D shapes instead of laminates) that cannot be achieved through a press stacking or coextrusion. Moreover, conversely to press stacking of different thicknesses on a substrate, through the use of a bi-material 3D printer, it allows to guarantee a constant thickness for a skin-core or sandwich structure.

The aim of this study was then to evaluate the advantages of additive manufacturing special features in order to improve the fire behaviour of PLA parts made by FFF. Different formulations of flame-retarded PLA based on ammonium polyphosphate, melamine cyanurate and nanoclays (phyllosilicates) were studied by changing their overall content and their distribution regarding the 
exposed surface. This approach implies manufacturing samples in which only the volume of flame retarded PLA was reduced (same FR concentration in the skin part), and samples in which all FR were concentrated in the skin part (same FR concentration in the whole part).

\section{Experimental}

\subsection{Materials}

Poly (lactic acid) Ingeo ${ }^{\mathrm{TM}}$ Biopolymer 7000D from NatureWorks was used in this study. In order to optimize its fire behaviour, the following FR were incorporated:

- Ammonium polyphosphate (APP): Exolit ${ }^{\circledR}$ AP 423 from Clariant; - Melamine cyanurate (MC): Melapur ${ }^{\circledR}$ MC 15 from BASF;

In addition, two types of phyllosilicates were used:

- Montmorillonite (organo-modified using methyl, tallow, bis-2hydroxyethyl, quaternary ammonium) (C30B): Cloisite ${ }^{\circledR 3}$ 30B from BYK;

- Sepiolite (unmodified) (PS9): Pangel S9 from Tolsa.

APP is well known as one of the main components of intumescent flame retardant (IFR) systems [20]. It acts in condensed phase promoting the formation of charred structure, caused by the phosphorylation of the polymer or added compounds present in the IFR. MC decomposes as cyanuric acid and melamine and its decomposition products, leading mainly to the emission of gaseous species able to dilute the combustible gases released by the polymer [21]. It has been shown in previous research works that $\mathrm{C} 30 \mathrm{~B}$ and PS9 phyllosilicates could exhibit synergistic effects with various flame retardants through mechanisms of formation of cohesive barriers able to limit mass and heat transfer of oxygen and volatile combustibles [5,22].

Five different compounds (F1, F2, F3, F4, F5) were processed, varying the amounts of the different FR in PLA. Five analogous compositions ( $\mathrm{F}^{\prime}, \mathrm{F} 2^{\prime}, \mathrm{F} 3^{\prime}, \mathrm{F} 4^{\prime}, \mathrm{F} 5$ ') with lower amounts of FR were also considered. Table 1 gives the contents of FR in PLA for all formulations.

\subsection{Processing}

For every formulation the flame retardants were incorporated into the PLA in a single step using a twin-screw co-rotative extruder BC21 (900 mm) from Clextral (France). An amount of each compound was used to produce $100 \times 100 \times 4 \mathrm{~mm}^{3}$ plates by injection moulding (hereafter indicated as INJ) with a KM 50-180 CX unit from Krauss Maffei (Germany).

The rest of each compound was used to produce calibrated filaments of $2.85 \mathrm{~mm}$ with a H2528 single extruder from Yvroud (France). The filament of each formulation was used in an A4v3 FFF machine from $3 n t r$ (Italy) in order to manufacture similar plates of $100 \times 100 \times 4 \mathrm{~mm}^{3}$. Nozzles of $0.4 \mathrm{~mm}$ in diameter were used to

Table 1

Studied formulations of flame-retarded PLA with respect to the FR contents [wt\%].

\begin{tabular}{llllllllllll}
\hline Material & PLA & F1 & F2 & F3 & F4 & F5 & F1 $^{\prime}$ & F2 $^{\prime}$ & F3 $^{\prime}$ & F4 $^{\prime}$ & F5 $^{\prime}$ \\
\hline PLA & 100 & 85 & 82 & 82 & 97 & 97 & 96.25 & 95.5 & 95.5 & 99.25 & 99.25 \\
APP & 0 & 12 & 12 & 12 & 0 & 0 & 3 & 3 & 3 & 0 & 0 \\
MC & 0 & 3 & 3 & 3 & 0 & 0 & 0.75 & 0.75 & 0.75 & 0 & 0 \\
C30B & 0 & 0 & 3 & 0 & 3 & 0 & 0 & 0.75 & 0 & 0.75 & 0 \\
PS9 & 0 & 0 & 0 & 3 & 0 & 3 & 0 & 0 & 0.75 & 0 & 0.75 \\
\hline
\end{tabular}

build $0.20 \mathrm{~mm}$ thick layers. The printing sequence was set as to deposit 2 contours for the outer shell of each layer and to alternate $+45^{\circ}$ and $-45^{\circ}$ infill patterns between every layer. For each sample, the printing lasted $4 \mathrm{~h}$.

Samples made by FFF (i.e. 3D printing) are hereafter named 3DP $\mathrm{X}$ mm where X stands for the thickness of flame-retarded PLA in the plate geometry. In this study, plates were either printed with a homogeneous distribution of the FR in the entire thickness of the plate (3DP $4 \mathrm{~mm}$ ) or with a heterogeneous skin-core structure (as in Fig. 1) having a skin thickness of $1 \mathrm{~mm}$ (3DP $1 \mathrm{~mm}$ ).

Depending on the formulation and the thickness of flameretarded PLA, the total FR content may vary in the whole sample, as illustrated in Table 2. In this way, for a given formulation and a given total FR content, both the effects of processing (i.e. injection vs. FFF) and FR distribution in printed samples (e.g. 3DP F1' $4 \mathrm{~mm}$ vs. 3DP F1 $1 \mathrm{~mm}$ ) on porosity and fire performance could be evaluated.

\subsection{Characterization}

\subsubsection{Density measurements}

Weight and dimensions of all samples were measured. Based on these values, the apparent density $\rho_{a p p}\left[\mathrm{~g} / \mathrm{cm}^{3}\right]$ was determined. Moreover, absolute density $\rho_{a b s}\left[\mathrm{~g} / \mathrm{cm}^{3}\right]$ was measured with an Accupyc 1330 helium pycnometer from Micromeritics (USA). Finally, porosity $\Phi[\%]$ was calculated according to the following equation:

$\Phi=100\left(1-\frac{\rho_{a p p}}{\rho_{a b s}}\right)$

\subsubsection{Scanning electron microscope}

The microstructures of samples and char residues after cone calorimeter tests were observed after carbon coating by means of a Quanta 200 FEG scanning electron microscope (SEM) from FEI Company (USA) equipped with an X-Max $80 \mathrm{~N}$ SDD detector.

\subsubsection{X-ray diffraction}

Samples and char residues were characterized by X-ray diffraction (XRD) with a Bruker AXS D8 Advance (Germany) equipped with a 1D Lynxeye CCD detector. Samples were scanned in the reflation mode using an incident $\mathrm{Cu}-\mathrm{K} \alpha$ radiation $(\lambda=1.5406 \AA)$, the monochromator was used at a voltage of $40 \mathrm{kV}$ and an intensity of $40 \mathrm{~mA}$. The scattering angle $2 \theta$ ranged from $5^{\circ}$ to $70^{\circ}$ with an interval of $0.0091^{\circ}$.

\section{Skin: Flame-retarded PLA}

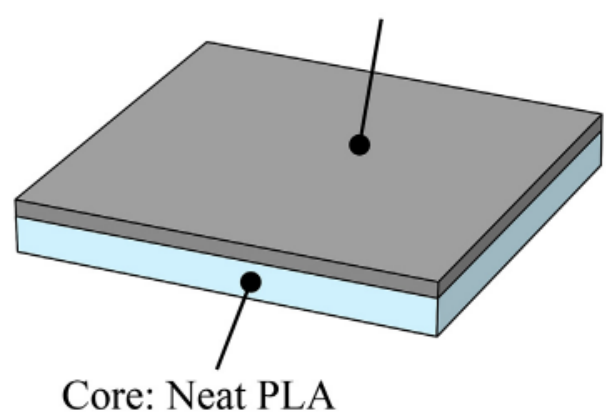

Fig. 1. Skin/core structure of 3DP samples $\left(100 \times 100 \times 4 \mathrm{~mm}^{3}\right)$. 
Table 2

Total FR content [wt\%] for each sample depending on its manufacturing process and the thickness of flame-retarded PLA.

\begin{tabular}{|c|c|c|c|c|c|c|c|c|c|c|c|}
\hline Processing & PLA & F1 & $\mathrm{F} 2$ & F3 & F4 & F5 & $\mathrm{F}^{\prime}{ }^{\prime}$ & $\mathrm{F} 2^{\prime}$ & F3' & $\mathrm{F} 4^{\prime}$ & $\mathrm{F}^{\prime}$ \\
\hline INJ & 0 & 15.0 & 18.0 & 18.0 & 3.00 & 3.00 & 3.75 & 4.50 & 4.50 & 0.75 & 0.75 \\
\hline 3DP $4 \mathrm{~mm}$ & 0 & 15.0 & 18.0 & 18.0 & 3.00 & 3.00 & 3.75 & 4.50 & 4.50 & 0.75 & 0.75 \\
\hline 3DP $1 \mathrm{~mm}$ & - & 3.75 & 4.50 & 4.50 & 0.75 & 0.75 & - & - & - & - & - \\
\hline
\end{tabular}

\subsubsection{Cone calorimeter}

Cone calorimetry is a well-established technique to evaluate flame retardancy of materials. It provides key parameters to assess flame retardant properties of materials. Tests were carried out with a cone calorimeter from Fire Testing Technology, according to the ISO 5660-1 standard. Irradiance provided by a cone-shaped inconel heating element was set to $50 \mathrm{~kW} / \mathrm{m}^{2}$ and each test was made at least in duplicate in order to assess reproducibility. The volatile combustibles from the burning sample were collected into an extraction hood situated directly above the cone heater. Heat release rate (HRR) $\left[\mathrm{kW} / \mathrm{m}^{2}\right]$ over the radiation time was measured by oxygen consumption using Hugget relation [23]. From these data, different key parameters can be obtained. These parameters are the peak of heat release rate (pHRR) $\left[\mathrm{kW} / \mathrm{m}^{2}\right]$, the time to ignition (TTI) [s] referring to the delay time between heat exposure and inflammation of the sample, the total heat released (THR) by the combustion $\left[\mathrm{MJ} / \mathrm{m}^{2}\right]$ and the effective heat of combustion (EHC) $[\mathrm{MJ} / \mathrm{kg}]$, that is the ratio of the THR to the mass loss. Another important parameter is the maximum average heat rate emission (MARHE) $\left[\mathrm{kW} / \mathrm{m}^{2}\right]$, which is the peak value of the cumulative heat emission over the time. The smoke production rate $\left[\mathrm{m}^{2} / \mathrm{s}\right]$ was also measured and the percent of char residue at the end of combustion was also considered.

The surface temperature of plates was measured as a function of time during cone calorimeter tests using a PI 160 thermal camera from Optris (Germany) with a focal length of $5.7 \mathrm{~mm}$. The camera was located at a distance of $50 \mathrm{~cm}$ to the sample. The emissivity was considered 0.9 [24] and the temperature was averaged on the sample surface. However, it is important to highlight that tests with the IR camera are not accurate to determine absolute temperatures but they remain interesting here to make qualitatively comparisons of thermal kinetics between injected and printed samples.

\section{Results}

\subsection{Microstructure}

Sepiolites are nanoparticles at natural state. Due to their good dispersion, they are present at nanometric scale in PLA as shown in Fig. S1 (supplementary material). The X-ray diffraction spectrum of C30B in PLA, displayed in Fig. S2 (supplementary material), exhibits an interlayer distance of $34.3 \AA$. Also, from DRX spectra, the organoclay alone presents an interlayer of $17 \AA$, which is close to the value obtained in other studies [25,26]. This result accounts for an intercalated structure corresponding also to a nanocomposite. To confirm the existence of a nanostructure, TEM micrographs were obtained (Fig. S3), showing individual silicate sheets and tactoïds.

Table 3

Mean porosity [\%] for sample type depending on its manufacturing process and its thickness of flame-retarded PLA.

\begin{tabular}{llllllllllll}
\hline Processing & PLA & F1 & F2 & F3 & F4 & F5 & F1 $^{\prime}$ & F2 $^{\prime}$ & F3 $^{\prime}$ & F4 $^{\prime}$ & F5 $^{\prime}$ \\
\hline INJ & 0 & 0.3 & 0.7 & 0.0 & 0.3 & 0.5 & 0.9 & 0.6 & 0.1 & 0.9 & 0.5 \\
3DP 4 mm & 5.7 & 18.3 & 7.5 & 11.2 & 6.3 & 7.0 & 4.7 & 11 & 2.8 & 2.5 & 2.0 \\
3DP 1 mm & - & 9.2 & 8.1 & 7.4 & 8.1 & 10.2 & - & - & - & - & - \\
\hline
\end{tabular}

Regarding the meso-structure of samples, Table 3 displays for each sample the values of mean porosity determined following Eq. (1), depending on the manufacturing process and the thickness of flame retarded PLA. It is possible to observe that samples manufactured by injection moulding have almost no porosity $(<1 \%)$. As expected for the FFF technique, results also exhibit a significant porosity for 3DP samples. However, porosity varies notably from one sample to another and highlights the difficulty to achieve a good reproducibility. In addition, no correlation can be made between samples' porosity and their formulations (the constituents and their contents or distribution).

A comparison of the microstructure of 3D printed specimen (F2 composition) with this of the corresponding injection moulding one was carried out. SEM images (Fig. 2a and b) show that the dispersion of the nanoclay and FR components is the same inside the filaments as in the injection moulded parts. It can be also noticed that $\mathrm{C} 30 \mathrm{~B}$ are dispersed at nanometric scale.

Samples' porosity was also observed by scanning electron micrographs highlighting the issues in printing PLA with FR (cf. Fig. 3a). Large spaces between filaments were observed in the cross sections of some printed samples. Further studies have to be carried out in order to optimize the processing parameters and to reduce porosities. However, SEM observations of interfaces between adjacent layers showed that no gaps were found between filaments of these layers, as illustrated in the magnification in Fig. $3 \mathrm{~b}$. These observations suggest that cohesive interfaces were formed during the deposition.

\subsection{Fire behaviour}

Fig. 4 shows the evolution of the HRR of INJ and 3DP $4 \mathrm{~mm}$ samples during cone calorimeter tests for the neat PLA and the F formulations. The shape of the HRR curves for formulations F1 to F4 exhibits a peak followed by a constant or slowly decreasing HRR value, which is characteristic of a charring process produced by APP [27]. It is possible to observe from the comparison between INJ and 3DP samples that for a same formulation there are only slight differences regarding the evolution of HRR over time. This means that the manufacturing process does not affect significantly the decomposition process of samples. However, as shown in Table 4, the THR seems to be slightly lower for 3DP samples. This is attributed to the lower mass of printed samples compared to the injected ones, as supported by porosity results in Table 3 .

Yet, the parameter that was the most affected by the process is the TTI (cf. Table 5). Indeed, the TTI decreased significantly for every formulation of 3DP samples. The difference in TTI was found to be up to $22 \mathrm{~s}$ for the neat PLA.

As expected, considering the influence of the formulation, it can be observed in Fig. 4 that adding a significant amount of FR systems into PLA improved its fire behaviour. This is characterized by a decrease of both THR (cf. Table 4) and pHRR (cf. Table 6), in particular for the formulations F1, F2, and F3. The formulations F2 and F3, for which APP and MC were combined with nanoclays, present the best performance. Indeed, considered separately, APP/ MC (F1), and C30B (F4) or PS9 (F5) were less efficient than used concomitantly, thus suggesting a strong synergy of these 


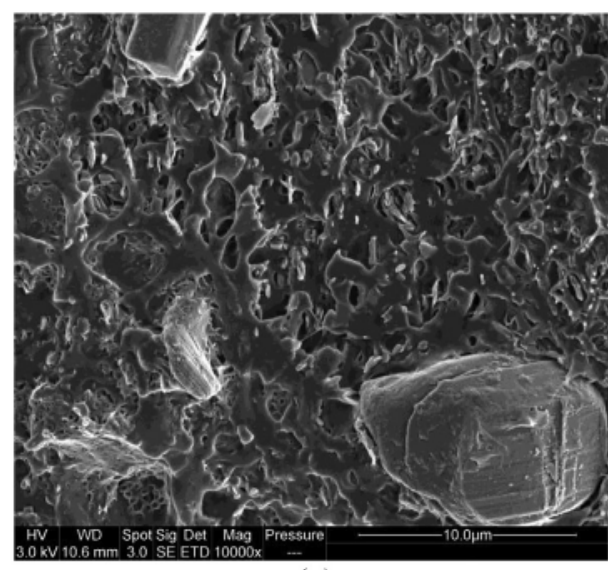

(a)

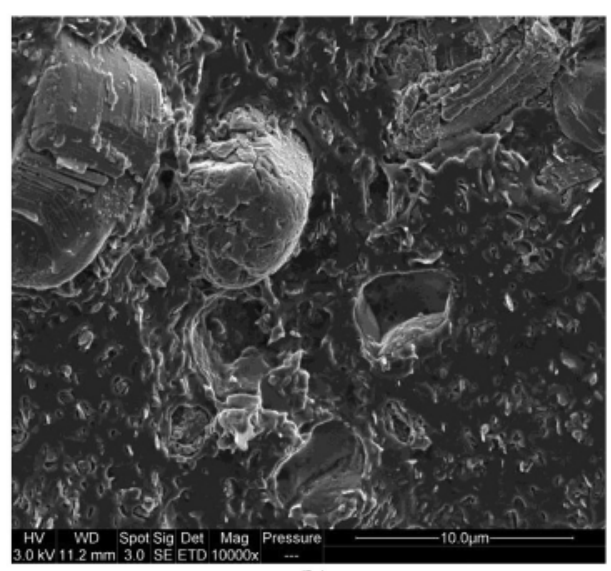

(b)

Fig. 2. SEM images of (a) the microstructure of an INJ F2 sample, (b) the microstructure of a 3DP 4 mm F2 sample.

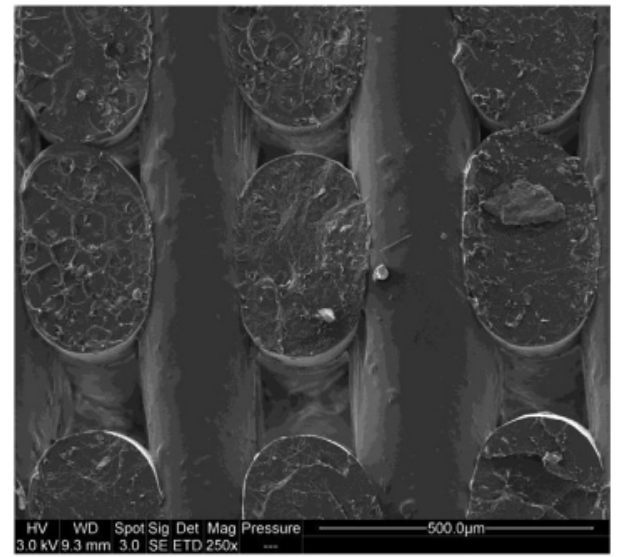

(a)

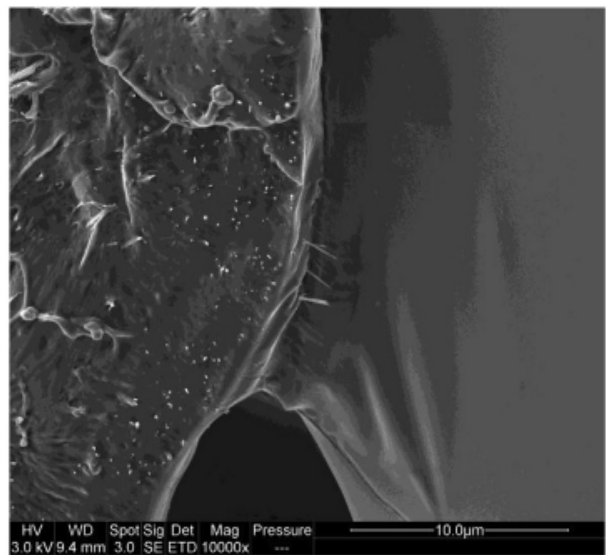

(b)

Fig. 3. Cross section of a 3DP F4 4 mm plate. (a) 5 layers orthogonal to the horizontal axis, (b) interface between 2 layers.

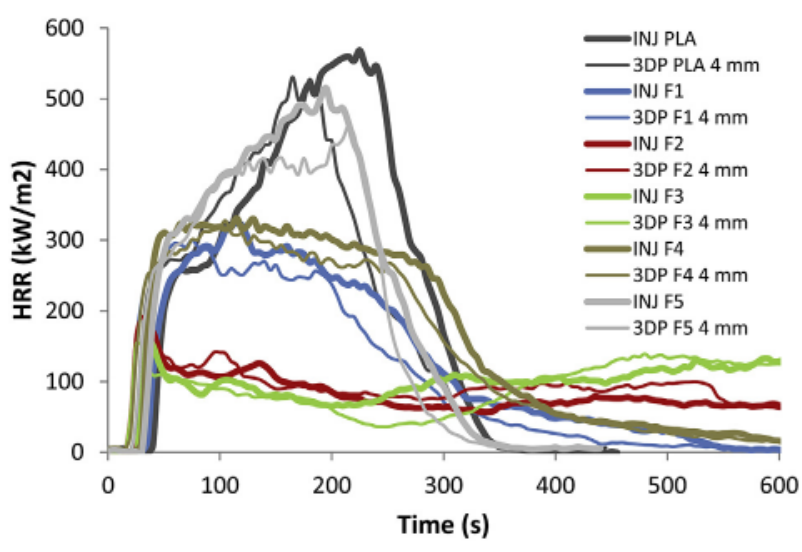

Fig. 4. HRR according to radiation time for INJ (thick) and 3DP $4 \mathrm{~mm}$ (thin) samples made of PLA, F1, F2, F3, F4 and F5.

constituents for decreasing the pHRR (cf. Table 6).

Regarding the FR content, Fig. 5 shows the five analogous compositions (F1', F2', F3', F4', F5') with lower amounts of FR fabricated by injection and FFF. Similarly to previous formulations, the TTI was also found to be significantly shortened for 3DP samples in comparison to INJ samples (cf. Table 5). Independently from
Table 4

Mean THR $\left[\mathrm{MJ} / \mathrm{m}^{2}\right]$ for sample type depending on its manufacturing process and its thickness of flame-retarded PLA.

\begin{tabular}{llllllllllll}
\hline Processing & PLA & F1 & F2 & F3 & F4 & F5 & F1 $^{\prime}$ & F2 $^{\prime}$ & F3 $^{\prime}$ & F4 $^{\prime}$ & F5 $^{\prime}$ \\
\hline INJ & 97 & 79 & 69 & 88 & 98 & 95 & 92 & 94 & 98 & 96 & 96 \\
3DP 4 mm & 90 & 67 & 68 & 73 & 89 & 86 & 84 & 84 & 93 & 97 & 93 \\
3DP 1 mm & - & 86 & 89 & 87 & 91 & 89 & - & - & - & - & - \\
\hline
\end{tabular}

Table 5

Mean TTI [s] for sample type depending on its manufacturing process and its thickness of flame-retarded PLA.

\begin{tabular}{llllllllllll}
\hline Processing & PLA & F1 & F2 & F3 & F4 & F5 & F1' & F2 $^{\prime}$ & F3 $^{\prime}$ & F4 & F5 $^{\prime}$ \\
\hline INJ & 46 & 37 & 28 & 27 & 33 & 33 & 32 & 29 & 27 & 37 & 36 \\
3DP 4 mm & 24 & 18 & 20 & 19 & 19 & 24 & 23 & 23 & 23 & 26 & 26 \\
3DP 1 mm & - & 23 & 20 & 19 & 23 & 22 & - & - & - & - & - \\
\hline
\end{tabular}

the process, the fire behaviour of all these samples presents, at best, very little improvement over neat PLA. This lack of efficiency is corroborated by the mean values of THR (cf. Table 4) and pHRR (cf. Table 6). It is attributed to the low concentration of APP which is not sufficient to provide a charring effect. Eventually, the decomposition mechanism of these samples is quite the same as neat PLA.

Regarding the distribution of the FR in the samples, the fire 
Table 6

Mean pHRR $\left[\mathrm{kW} / \mathrm{m}^{2}\right]$ for sample type depending on its manufacturing process and its thickness of flame-retarded PLA

\begin{tabular}{llllllllllll}
\hline Processing & PLA & F1 & F2 & F3 & F4 & F5 & F1 & F2 & F3' & F4 & F5' \\
\hline INJ & 569 & 323 & 178 & 165 & 330 & 514 & 520 & 413 & 505 & 542 & 525 \\
3DP 4 mm & 532 & 300 & 197 & 156 & 319 & 442 & 512 & 459 & 504 & 515 & 590 \\
3DP 1 mm & - & 481 & 310 & 240 & 486 & 531 & - & - & - & - & - \\
\hline
\end{tabular}

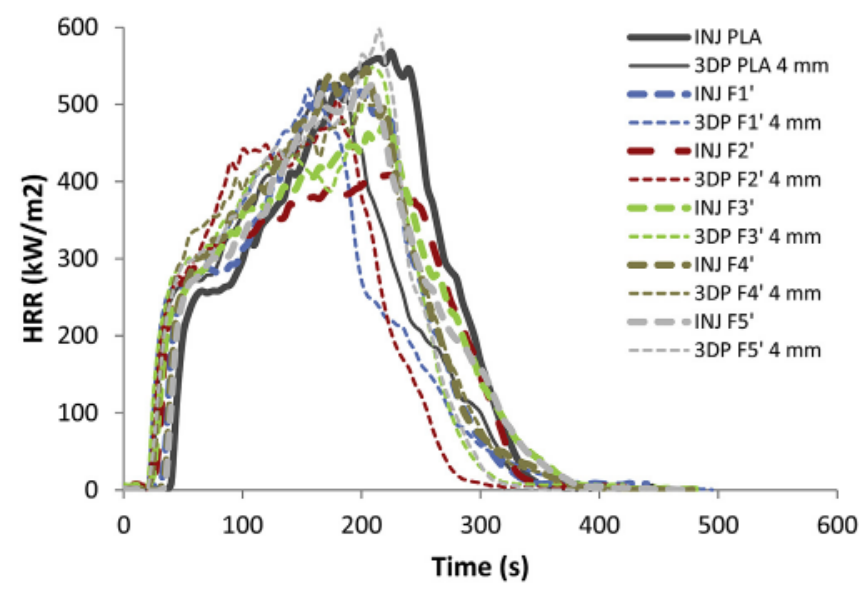

Fig. 5. HRR according to radiation time for INJ (thick dashed) and 3DP $4 \mathrm{~mm}$ (thin dashed) samples made of PLA, F1', F2', F3', F4' and F5'.

behaviour of skin/core structures (i.e. 3DP $1 \mathrm{~mm}$ ) can be compared in Fig. 6 to samples with homogeneous FR distribution and the same total FR content (i.e. 3DP $4 \mathrm{~mm}$ samples of $\mathrm{F}^{\prime}$ formulations). It was found that placing the FR in the first millimetre thickness of the plate improved drastically the fire behaviour. The same amount of FR, which was found to be inefficient if distributed in the whole sample, became more efficient if FR were concentrated close to the irradiated surface. These results are coherent with previous studies where dual structures for a unique polymer were obtained by means of other technologies, such as press stacking and coating $[14,18,28]$, showing the beneficial effects of concentrating the FR in the top layer of sample compared to a homogeneous FR distribution. Here in particular, the pHRR value of 3DP F3 $1 \mathrm{~mm}$ was halved compared to 3DP F3' $4 \mathrm{~mm}$. However, Table 5 suggests a slightly lower TTI for skin/core structures, but this difference is slight and correlated to the higher porosity of these samples. The TTI

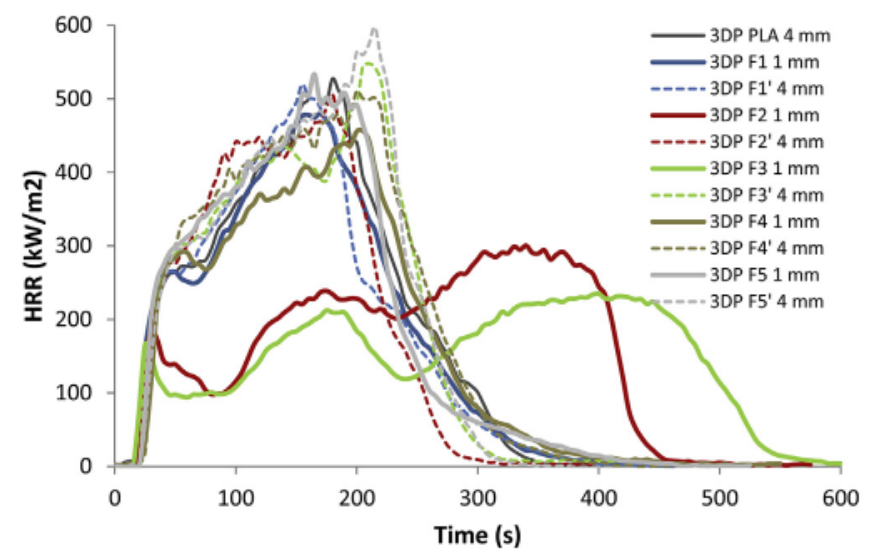

Fig. 6. HRR according to radiation time for 3DP samples depending on FR distribution (solid line: in the whole sample, that is 3DP $4 \mathrm{~mm}$ samples, dashed line: in the first $\mathrm{mm}$, that is 3DP $1 \mathrm{~mm}$ ). dependence on porosity in relation to other parameters such as the process, the FR content and the FR distribution is detailed in the discussion section.

\section{Discussion}

Cone calorimeter tests demonstrated that a considerable synergy occurred between APP/MC and nanoclays (both C30B and PS9) [29]. Indeed considered separately, the presence of these constituents in PLA improved poorly its fire behaviour (e.g. F1 and F4) or not at all (e.g. F1', F4', F5, and F5'). However, used concomitantly, APP, MC and nanoclays helped decreasing drastically the pHRR thanks to the creation of a protective layer (char) on PLA residue, which limited heat and mass transfer (Fig. 7).

As it can be observed, the aspect of this layer appears different depending on the formulation. Without nanoclay, the residue corresponds to this of a "pure intumescent system" with a charred and expanded structure (cf. Fig. 7b). Conversely, in the presence of C30B (cf. Fig. 7b) or SP9 (cf. Fig. 7c) combined with the same components, the residues are also expanded but their surface seems more cohesive, in particular for SP9. Previous studies demonstrated that compositions with sepiolite could induce the in situ formation of phosphates, such as silicon pyrophosphate and ammonium magnesium phosphate $[5,22]$. These phosphates can form from $350^{\circ} \mathrm{C}$ and consequently are prone to protect quickly the polymer and to contribute significantly to the decrease of the pHRR. To confirm this point for the present study, final residues of 3DP $4 \mathrm{~mm}$ and 3DP $1 \mathrm{~mm}$ samples for the F2 and F3 compositions were analysed using X-Rays diffraction (Fig. 8). It can be shown that, even for an initial $1 \mathrm{~mm}$ thickness of intumescent flame retardant system, the in situ formation of phosphates was achieved, leading to a protective effect of the residual material against the irradiation. In the case of F2 composition, only the formation of $\mathrm{SiP}_{2} \mathrm{O}_{7}$ can be noticed, whereas in the case of $\mathrm{F} 3$ compositions, a second kind of phosphate $\mathrm{NH}_{4} \mathrm{Mg}\left(\mathrm{PO}_{3}\right)_{3}$ also appeared. This additional product might explain the results suggesting the slight advantage of SP9 over C30B as synergistic agent, as shown by pHRR values of 3DP F2 $1 \mathrm{~mm}$ and 3DP F3 $1 \mathrm{~mm}$ (240 and $310 \mathrm{~kW} / \mathrm{m}^{2}$ respectively).

The results also showed that the distribution of the FR could be decisive in their efficiency. Indeed, having FR concentrated close to the radiated surface (3DP F $1 \mathrm{~mm}$ ) instead of being spread within the whole sample (3DP $F^{\prime} 4 \mathrm{~mm}$ ), led to a completely different evolution of the HRR in the case of F2 and F3 (cf. Fig. 6). While the behaviour of 3DP F2' $4 \mathrm{~mm}$ and 3DP F3' $4 \mathrm{~mm}$ did not change much from neat PLA, the pHRR of 3DP F2 $1 \mathrm{~mm}$ and 3DP F3 $1 \mathrm{~mm}$ decreased by $32 \%$ and $52 \%$ respectively. In the case of 3DP F $1 \mathrm{~mm}$, the FR components were more concentrated and located at the irradiated surface, and thus lead to an higher intensity of char formation, while in the case of 3DP F $4 \mathrm{~mm}$, the formation of the layer was weaker since FR components were distributed in the whole thickness of the samples. Therefore, in this case, the thermal ablation of the polymer was faster, leading to a lesser flame retardancy [18].

The difference in TTI, and in a lesser extent in THR, between INJ and 3DP samples was explained by the lower mass of the 3DP samples because of their higher porosity (similar apparent volume).

Concerning the THR, a lower mass induces lesser fuel in the combustion reaction, meaning a lower energy release. This is supported by the EHC values which are globally rather similar (around $17 \mathrm{MJ} / \mathrm{kg}$ ), as shown in Table 7. In order to provide a better comparison of the various HRR curves, data of MARHE are also indicated in Table 8. It can be noticed that MARHE values are overall in accordance with pHRR data. Moreover, there is no significant difference between injection moulding and 3DP $4 \mathrm{~mm}$ specimens. 


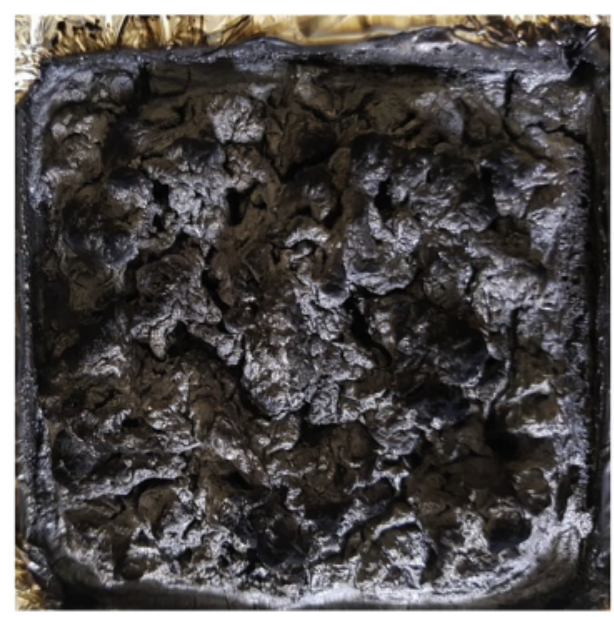

(a)

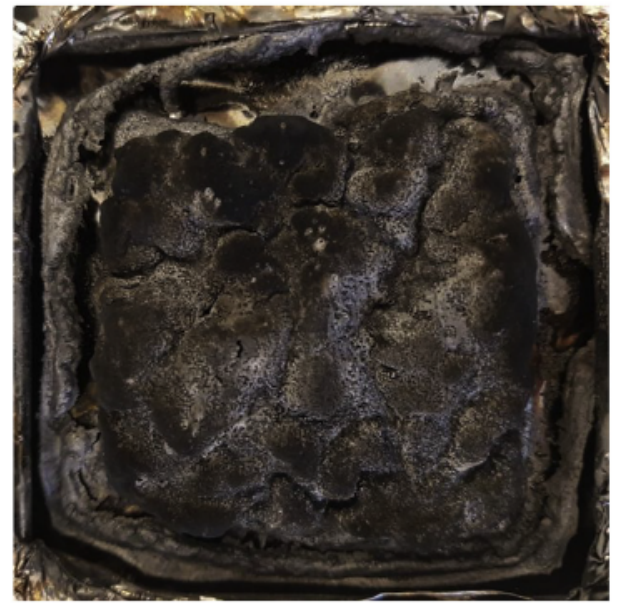

(b)

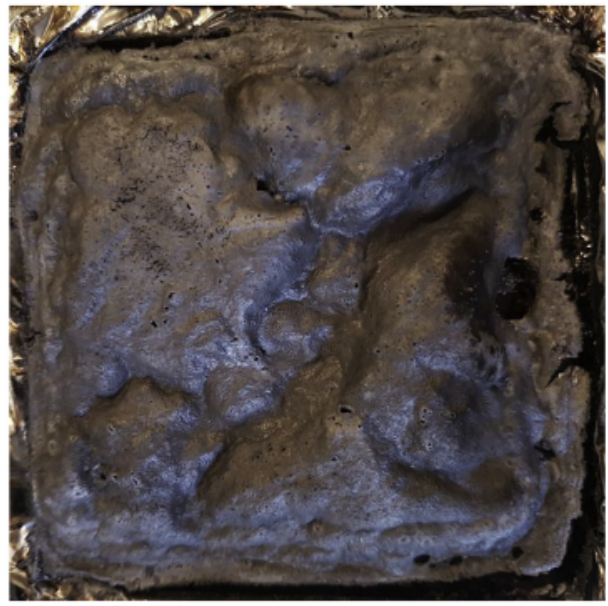

(c)

Fig. 7. 3DP F1 $4 \mathrm{~mm}$ (a), 3DP F2 $1 \mathrm{~mm}$ (b) and 3DP F3 $1 \mathrm{~mm}$ (c) plates after a cone calorimeter test highlighting the presence of a char layer.

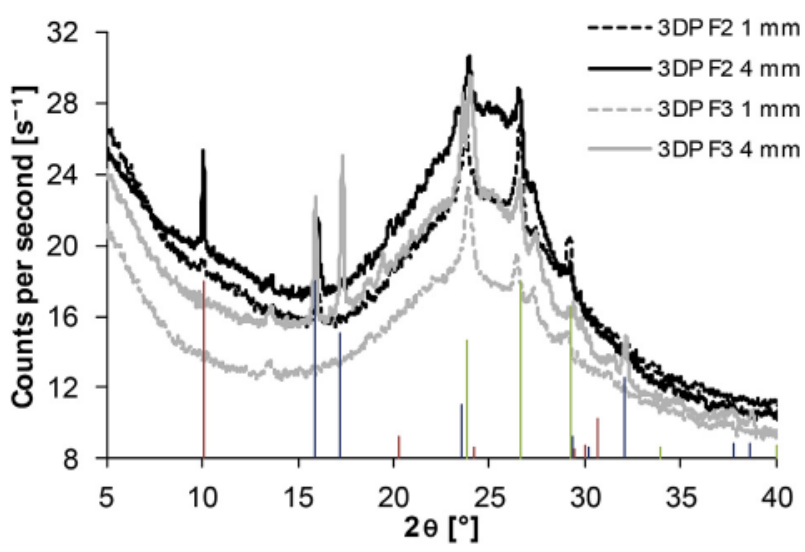

Fig. 8. X-rays diffraction patterns of residues of 3DP $4 \mathrm{~mm}$ and 3DP $1 \mathrm{~mm}$ samples for $\mathrm{F} 2$ and $\mathrm{F} 3$ compositions (diffraction patterns of $\mathrm{SiP}_{2} \mathrm{O}_{7}$ in green, $\mathrm{NH}_{4} \mathrm{Mg}\left(\mathrm{PO}_{3}\right)_{3}$ in blue, and $\mathrm{AlH}_{6}\left(\mathrm{PO}_{4}\right)_{3} 2 \mathrm{H}_{2} \mathrm{O}$ in red).. (For interpretation of the references to colour in this figure legend, the reader is referred to the Web version of this article.)

Concerning the TTI, it was clearly observed the influence of the porosity of 3DP samples on its value. Even though numerous other factors may affect the TTI, porosity was one of the most important. This dependence becomes clear comparing zooms on the TTI of
HRR vs time curves and correlating porosity measurements in Table 3 to these curves (Fig. 9). It is possible to observe in Fig. 9 that more significant was the difference in porosity ranges between two types of samples, more significant was the difference in TTI. In particular, injected and 3DP samples with the highest amount of FR (INJ vs 3DP F $4 \mathrm{~mm}$ ) had the most significant differences in porosity and also in TTI. Formulations with a lower amount of FR (INJ vs 3DP $\mathrm{F}^{\prime} 4 \mathrm{~mm}$ ) presented a lower difference in porosity range and also in TTI. Finally, between printed samples with FR distributed homogeneously and ones with FR concentrated on surface (3DP F $4 \mathrm{~mm}$ vs $3 \mathrm{DP} F \mathrm{~mm}$ ) there was no significant difference in porosity ranges and neither in TTI.

Higher porosity causes lower mass of the samples and then a lower heat capacity that makes the temperature increase faster. This statement was confirmed by some temperature measurements during cone calorimeter tests using a thermal camera (cf. Fig. 10). At $\mathrm{t}=0 \mathrm{~s}$ the thermal camera measures temperature of sample that is already heating. The beginning of the cone calorimeter test is detected by the thermal camera recording a small peak of temperature (Fig. 10). Then the temperature rises up to a slight plateau indicating the degradation of polymer, followed by the ignition. It is possible to observe in Fig. 10 that the temperature of ignition did not change significantly between the neat PLA and the printed and injected $\mathrm{F}$ 1, but the heating kinetic was significantly faster for the printed sample than for the injected ones. Hence, faster is the 
Table 7

Mean EHC $[\mathrm{MJ} / \mathrm{kg}]$ for sample type depending on its manufacturing process and its thickness of flame-retarded PLA.

\begin{tabular}{|c|c|c|c|c|c|c|c|c|c|c|c|}
\hline Processing & PLA & $\mathrm{F} 1$ & $\mathrm{~F} 2$ & F3 & F4 & F5 & $\mathrm{F}^{\prime}$ & $\mathrm{F} 2^{\prime}$ & $\mathrm{F}^{\prime}$ & $\mathrm{F} 4^{\prime}$ & $\mathrm{F}^{\prime}$ \\
\hline INJ & 17.9 & 15.7 & 13.6 & 17.3 & 17.3 & 17.6 & 16.8 & 17.3 & 16.7 & 17.5 & 17.5 \\
\hline 3DP $4 \mathrm{~mm}$ & 17.4 & 15.8 & 14.7 & 15.0 & 17.5 & 17.3 & 16.4 & 17.0 & 17.2 & 17.5 & 17.3 \\
\hline 3DP $1 \mathrm{~mm}$ & - & 16.6 & 16.6 & 16.3 & 17.2 & 17.4 & - & - & - & - & - \\
\hline
\end{tabular}

Table 8

Mean MARHE $\left[\mathrm{kW} / \mathrm{m}^{2}\right]$ for sample type depending on its manufacturing process and its thickness of flame-retarded PLA.

\begin{tabular}{llllllllllll}
\hline Processing & PLA & F1 & F2 & F3 & F4 & F5 & F1 $^{\prime}$ & F2 $^{\prime}$ & F3 $^{\prime}$ & F4 $^{\prime}$ & F5 $^{\prime}$ \\
\hline INJ & 340 & 227 & 94 & 98 & 265 & 344 & 334 & 308 & 334 & 338 & 334 \\
3DP 4 mm & 332 & 217 & 110 & 96 & 255 & 348 & 329 & 324 & 334 & 358 & 353 \\
3DP 1 mm & - & 315 & 211 & 169 & 329 & 354 & - & - & - & - & - \\
\hline
\end{tabular}

heating kinetic, lower is the TTI [30].

\section{Conclusions}

The aim of this study was to identify an appropriate strategy to manufacture 3D printed parts made of flame-retarded PLA by assessing the influence of different compositions made of ammonium polyphosphate, melamine cyanurate and nanoclays, the influence of the total amount of FR, and the influence of the FR spatial distribution in PLA.

Results from cone calorimeter tests showed that, compared to injected samples, samples made by FFF exhibited a significant decrease in the time to ignition and a slight decrease in the total heat released. This behaviour was mainly attributed to the higher sample porosity (i.e. lower mass) induced by the FFF process. Regarding the formulations, the considerable synergy of nanoclays with the other FR components, makes these compositions the most promising in order to decrease the pHRR of flame-retarded PLA.

The most important result of this study would be the benefit of concentrating the FR system close to the radiated surface, in order to induce the early formation of a char layer. In fact, the implementation of this kind of structure turns out to be very straightforward even for complex parts. Slicing softwares could be used to attribute flame-retarded PLA to all outer shells (i.e. outlines, bottom, and top layers) while the infill structure could be made only of
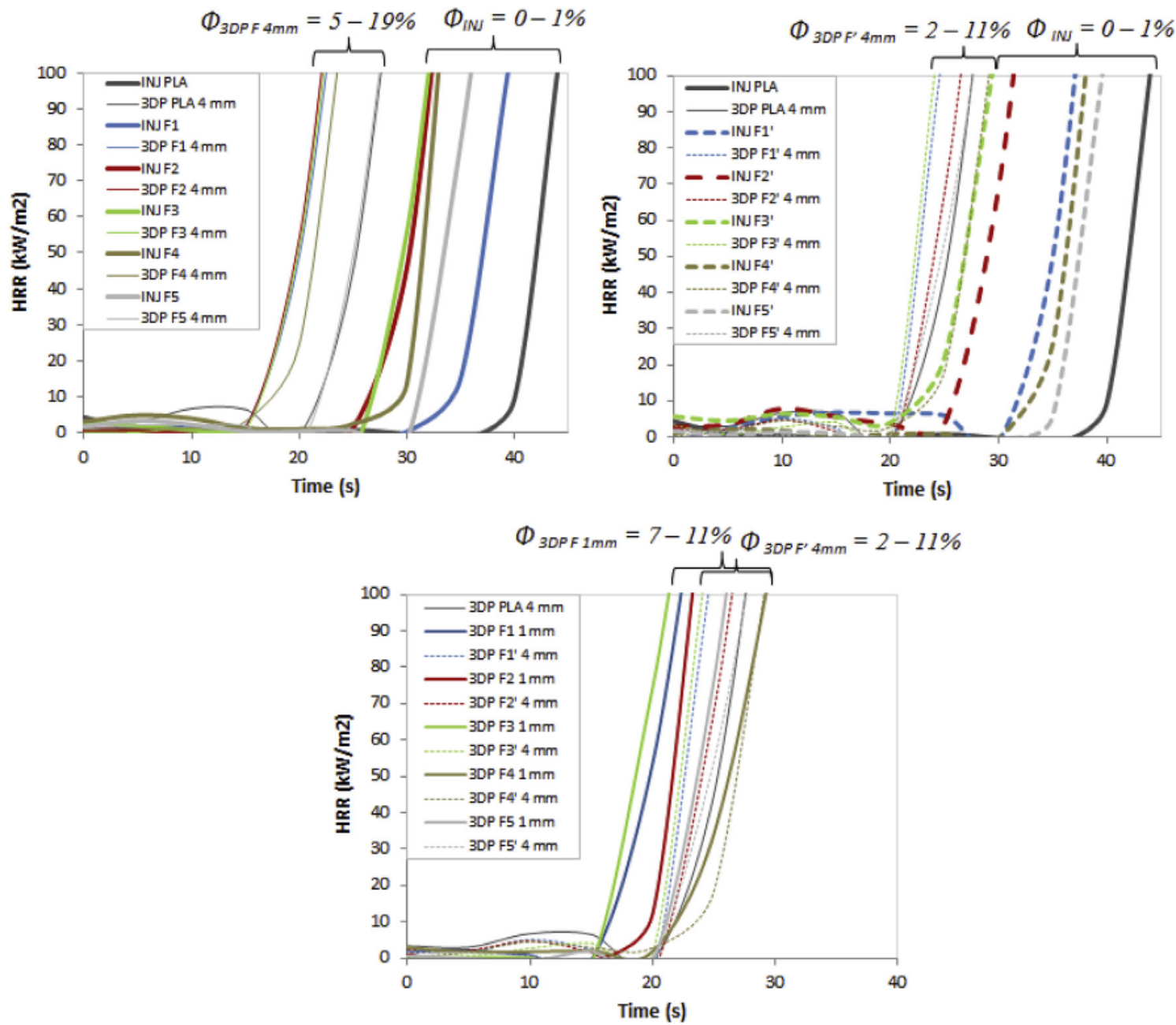

Fig. 9. Zoom of the first $45 \mathrm{~s}$ of HRR according to radiation time for all tested samples. 


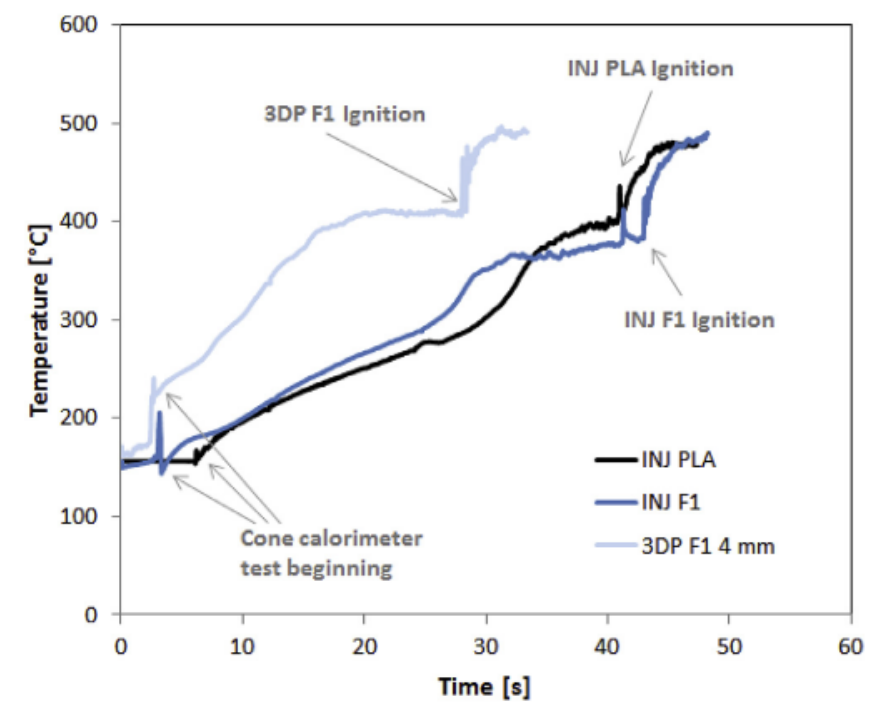

Fig. 10. Temperature during cone calorimeter tests of INJ PLA, INJ F1, and 3DP F1 $4 \mathrm{~mm}$.

pure PLA, thus preserving its mechanical properties.

To extend this study, it would be particularly interesting to assess the improvement on mechanical properties but also to increase the FR content in the skin part in order to improve the fire behaviour and/or to lower the skin thickness.

\section{Appendix A. Supplementary data}

Supplementary data to this article can be found online at https://doi.org/10.1016/j.polymdegradstab.2019.03.008.

\section{References}

[1] R.T.L. Ferreira, I.C. Amatte, T.A. Dutra, D. Bürger, Experimental characterization and micrography of 3D printed PLA and PLA reinforced with short carbon fibers, Compos. B Eng. 124 (2017) 88-100, https://doi.org/10.1016/ j.compositesb.2017.05.013.

[2] M. Murariu, P. Dubois, PLA composites: from production to properties, Adv. Drug Deliv. Rev. 107 (2016) 17-46, https://doi.org/10.1016/ j.addr.2016.04.003.

[3] M. Murariu, F. Laoutid, P. Dubois, G. Fontaine, S. Bourbigot, E. Devaux, C. Campagne, M. Ferreira, S. Solarski, Pathways to biodegradable flame retardant polymer (Nano)Composites, in: Polym. Green Flame Retard, Elsevier, 2014, pp. 709-773, https://doi.org/10.1016/B978-0-444-53808-6.000214.

[4] S. Bourbigot, G. Fontaine, Flame retardancy of polylactide: an overview, Polym. Chem. 1 (2010) 1413, https://doi.org/10.1039/c0py00106f.

[5] L. Dumazert, D. Rasselet, B. Pang, B. Gallard, S. Kennouche, J.-M. Lopez-Cuesta, Thermal stability and fire reaction of poly(butylene succinate) nanocomposites using natural clays and FR additives, Polym. Adv. Technol. 29 (2018) 69-83, https://doi.org/10.1002/pat.4090.

[6] Y. Guo, C.-C. Chang, G. Halada, M.A. Cuiffo, Y. Xue, X. Zuo, S. Pack, L. Zhang, S. He, E. Weil, M.H. Rafailovich, Engineering flame retardant biodegradable polymer nanocomposites and their application in 3D printing, Polym. Degrad.

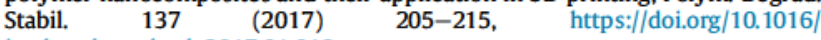
j.polymdegradstab.2017.01.019.

[7] I. Zembouai, S. Bruzaud, M. Kaci, A. Benhamida, Y.-M. Corre, Y. Grohens, J.M. Lopez-Cuesta, Synergistic effect of compatibilizer and cloisite $30 \mathrm{~B}$ on the functional properties of poly(3-hydroxybutyrate- co -3-hydroxyvalerate)/ polylactide blends, Polym. Eng. Sci. 54 (2014) 2239-2251, https://doi.org/ 10.1002/pen.23776.

[8] K. Fukushima, M. Murariu, G. Camino, P. Dubois, Effect of expanded graphite/ layered-silicate clay on thermal, mechanical and fire retardant properties of poly(lactic acid), Polym. Degrad. Stabil. 95 (2010) 1063-1076, https://doi.org/ 10.1016/j.polymdegradstab.2010.02.029.

[9] K.-C. Cheng, C.-B. Yu, W. Guo, S.-F. Wang, T.-H. Chuang, Y.-H. Lin, Thermal properties and flammability of polylactide nanocomposites with aluminum trihydrate and organoclay, Carbohydr. Polym. 87 (2012) 1119-1123, https:// doi.org/10,1016/j.carbpol.2011.08.065.

[10] S. Solarski, F. Mahjoubi, M. Ferreira, E. Devaux, P. Bachelet, S. Bourbigot, R. Delobel, P. Coszach, M. Murariu, A. Da silva Ferreira, M. Alexandre, P. Degee, P. Dubois, (Plasticized) Polylactide/clay nanocomposite textile: thermal, mechanical, shrinkage and fire properties, J. Mater. Sci. 42 (2007) 5105-5117. https://doi.org/10.1007/s10853-006-0911-0.

[11] G. Fontaine, S. Bourbigot, Intumescent polylactide: a nonflammable material, J. Appl. Polym. Sci. 113 (2009) 3860-3865, https://doi.org/10.1002/app.30379.

[12] A. Regazzi, M.F. Pucci, L. Dumazert, S. Buonomo, B. Gallard, R. Ravel, J.-M. Lopez-Cuesta, Development of flame-retarded PLA compositions by 3D printing of core-skin structures, in: ECCM18 - 18th Eur. Conf. Compos. Mater. Athens, Greece, n.d.

[13] M. Gomes, D. Martino, A.J. Pontes, J.C. Viana, Co-injection molding of immiscible polymers: skin-core structure and adhesion studies, Polym. Eng. Sci. 51 (2011) 2398-2407, https://doi.org/10.1002/pen.22012.

[14] P.R. Hornsby, R.N. Rothon, Fire retardant fillers for polymers, in: M. Le Bras, S. Bourbigot, S. Duquesne, C. Jama, C. Wilkie (Eds.), Fire Retard. Polym, Royal Society of Chemistry, Cambridge, 2005, pp. 19-41, https://doi.org/10.1039/ 9781847552396-00017.

[15] J. Liu, Z. Yu, Y. Shi, H. Chang, Y. Zhang, J. Luo, C. Lu, A preliminary study on the thermal degradation behavior and flame retardancy of high impact polystyrene/magnesium hydroxide/microencapsulated red phosphorus composite with a gradient structure, Polym. Degrad. Stabil. 105 (2014) 21-30, https:/ doi.org/10.1016/j.polymdegradstab.2014.03.034.

[16] Z. Yu, J. Liu, Y. Zhang, J. Luo, C. Lu, B. Pan, Thermo-oxidative degradation behavior and fire performance of high impact polystyrene/magnesium hydroxide/microencapsulated red phosphorus composite with an alternating layered structure, Polym. Degrad. Stabil. 115 (2015) 54-62, https://doi.org/ 10.1016/j.polymdegradstab.2015.02.015.

[17] M. Jimenez, S. Duquesne, S. Bourbigot, Characterization of the performance of an intumescent fire protective coating, Surf. Coating. Technol. 201 (2006) 979-987, https://doi.org/10.1016/j.surfcoat.2006.01.026.

[18] E. Gallo, B. Schartel, D. Acierno, F. Cimino, P. Russo, Tailoring the flame retardant and mechanical performances of natural fiber-reinforced biopolymer by multi-component laminate, Compos. B Eng. 44 (2013) 112-119, https://doi.org/10.1016/j.compositesb.2012.07.005.

[19] M.V.C. Morais, R. Reidel, P. Weiss, S. Baumann, C. Hubner, F. Henning, Integration of electronic components in the thermoplastic processing chain: possibilities through additive manufacturing using conductive materials, in: 2018 13th Int. Congr. Molded Interconnect Devices, IEEE, 2018, pp. 1-4, https://doi.org/10.1109/ICMID.2018.8527054.

[20] G. Camino, L. Costa, L. Trossarelli, Study of the mechanism of intumescence in fire retardant polymers: Part I-thermal degradation of ammonium polyphosphate-pentaerythritol mixtures, Polym. Degrad. Stabil. 6 (1984) 243-252, https://doi.org/10.1016/0141-3910(84)90004-1.

[21] S.V. Levchik, G.F. Levchik, A.I. Balabanovich, G. Camino, L. Costa, Mechanistic study of combustion performance and thermal decomposition behaviour of nylon 6 with added halogen-free fire retardants, Polym. Degrad. Stabil. 54 (1996) 217-222, https://doi.org/10.1016/S0141-3910(96)00046-8.

[22] H. Vahabi, R. Sonnier, B, Otazaghine, G Le Saout, J. Lopez-Cuesta, Nanocomposites of polypropylene/polyamide 6 blends based on three different nanoclays: thermal stability and flame retardancy, Polimery 58 (2013) 350-360, https://doi.org/10.14314/polimery.2013.350.

[23] C. Huggett, Estimation of rate of heat release by means of oxygen consumption measurements, Fire Mater. 4 (1980) 61-65, https://doi.org/10.1002/ fam. 810040202 .

[24] J.A. Cicero, J.R. Dorgan, Physical properties and fiber morphology of poly(lactic acid) obtained from continuous two-step melt spinning, J. Polym. Environ. 9 (2001) 1-10, https://doi.org/10.1023/A:1016012818800.

[25] S. Filippi, M. Paci, G. Polacco, N.T. Dintcheva, P. Magagnini, On the interlayer spacing collapse of Cloisite ${ }^{8}$ 30B organoclay, Polym. Degrad. Stabil. 96 (2011) 823-832, https://doi.org/10.1016/J.POLYMDEGRADSTAB.2011.02.008.

[26] S.-G. Kim, E.A. Lofgren, S.A. Jabarin, Dispersion of nanoclays with poly(ethylene terephthalate) by melt blending and solid state polymerization J. Appl. Polym. Sci. 127 (2013) 2201-2212, https://doi.org/10.1002/app.37796.

[27] B. Schartel, T.R. Hull, Development of fire-retarded materials-interpretation of cone calorimeter data, Fire Mater. 31 (2007) 327-354, https://doi.org $10.1002 /$ fam.949.

[28] M. Morys, B. Illerhaus, H. Sturm, B. Schartel, Size is not all that matters: residue thickness and protection performance of intumescent coatings made from different binders, J. Fire Sci. 35 (2017) 284-302, https://doi.org/10.1177/ 0734904117709479.

[29] S. Hazer, M. Coban, A. Aytac, Effects of the nanoclay and intumescent system on the properties of the plasticized polylactic acid, Acta Phys. Pol., A 132 (2017) 634-637, https://doi.org/10.12693/APhysPolA.132.634.

[30] A. Fina, F. Cuttica, G. Camino, Ignition of polypropylene/montmorillonite nanocomposites, Polym. Degrad. Stabil. 97 (2012) 2619-2626, https://doi.org 10.1016/j.polymdegradstab.2012.07.017. 